\title{
Dynamics of developmental stability of seals and pollution in the Baltic Sea
}

\author{
Vladimir M. ZAKHAROV, Alexey V. VALETSKY and Alexey V. YABLOKOV
}

\begin{abstract}
Zakharov V. M., Valetsky A. V. and Yablokov A. V. 1997. Dynamics of developmental stability of seals and pollution in the Baltic Sea. [In: Developmental homeostasis in natural populations of mammals: phenetic approach. V. M. Zakharov and A. V. Yablokov, eds]. Acta Theriologica, Suppl. 4: 9-16.
\end{abstract}

Fluctuating asymmetry of skull characters, as a measure of developmental stability, was studied in two seal species: grey seal Halichoerus grypus (Fabricius, 1791), and ringed seal Pusa hispida Schreber, 1775 from the Baltic Sea. Seals were collected in three different periods of water pollution of the Baltic Sea. We revealed the same temporal dynamics of fluctuating asymmetry level for both species: it proved to be low in "pre-pollution period" (years 1877-1936), high for the "high-pollution period" (1964-1975), and was again low for the "low-pollution period" (1986-1990). These data suggest that changes in the condition of the seal populations in the Baltic Sea revealed by changes in developmental stability are correlated with the dynamics of the pollution level.

N. K. Koltzov Institute of Developmental Biology Russian Academy of Sciences, Vavilov Str. 26, Moscow, 117808 Russia

Key words: Halichoerus grypus, Pusa hispida, non-metric traits, fluctuating asymmetry, developmental stability, pollution

\section{Introduction}

The lowest level of phenotype diversity caused by the ontogenetic disturbances corresponds to the high developmental stability (Mather 1953). Fluctuating asymmetry, as differences between the two sides of the body that cannot be explained by either genetic or environmental differences, is a common measure of the level of developmental stability (Zakharov 1981, Palmer and Strobeck 1986). In practice, it could be measured by the variance of minor non-directional differences between the paired structures on the left and on the right sides of the body. High developmental stability (low fluctuating asymmetry) corresponds to the development of well-coadapted genotypes under optimal environmental conditions. Its deterioration can be seen under the impact of the stress. Some data have been revealed for the pollution impact on various species, including seals (Valentine and Soulè 1973, Zakharov and Yablokov 1990, Pankakoski et al. 1992).

Earlier investigations have revealed a dramatic decrease in numbers of the two most common seal species in the Baltic Sea: the ringed seal Pusa hispida Schreber, 
1775 and grey seal Halichoerus grypus (Fabricius, 1791) (Olsson et al. 1975, Helle et al. 1976a, b). This is presumably caused by the high levels of various pollutants, primarily organochlorines, present in the Baltic fish that make up the diet of the seals (Bergman and Olsson 1985). The most dramatic increase in levels of two of the major organochlorines, namely DDT and PCB, occurred after 1955 (Olsson et al. 1975). At present, input of known environmental pollutants in the Baltic Sea is decreasing (Fig. 1) (Olsson and Reutergärdh 1986) and some indications of improvement of the seal populations here have been already registered (Blomkvist et al. 1992).

The task of this study is to answer the question whether changes in developmental stability, as a parameter of the condition of natural populations (Valentine et al. 1973, Jones 1987, Leary and Allendorf 1989, Zakharov 1989, 1990 ), could be found in the Baltic populations of the ringed seal and grey seal during periods of the increase and then decrease of the pollution level. Deterioration effect of the increased pollution of the Baltic Sea has been already found in seal populations and quantified by developmental stability level (Zakharov et al. 1989a, b, Zakharov and Yablokov 1990). The main aim of this study is to reveal possible recovery changes in recent years of lowered pollution.

Such an attempt seems to be important for both to answer the question whether there are positive changes in the condition of the seal populations in the Baltic Sea as well as to test applicability of developmental stability study. Reversibility of the ontogenetic accidents registered by the measures of developmental stability (Zakharov 1987, 1990) makes this approach promising for the positive answer to the latter question. Our prediction is that changes in the level of developmental stability of seals in the Baltic Sea should follow already established dynamics of the level of pollution in the area.

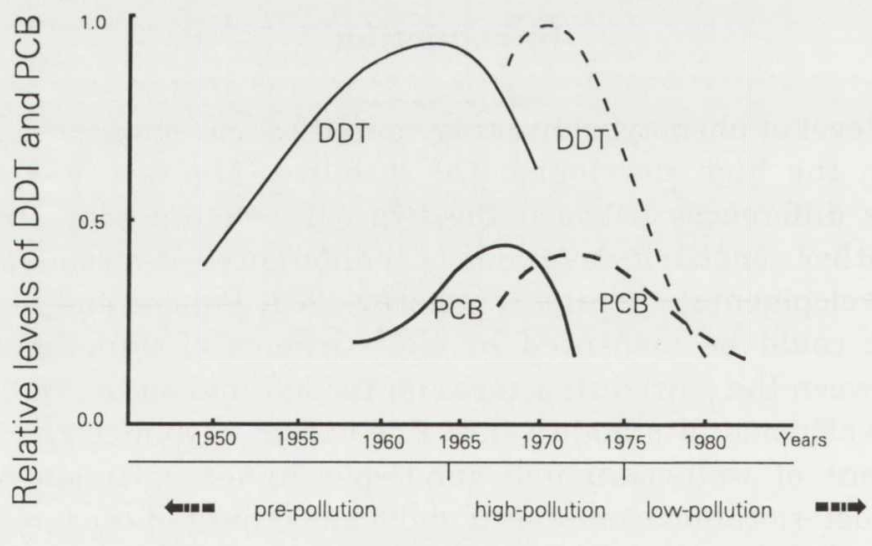

Periods

Fig. 1. Dynamics of pollution in the Baltic Sea. Variation of known industrial production of DDT and PCB (solid lines), and their relative levels in guillemot Uria spp. eggs (broken lines). From Olsson and Reutergärdh 1986, modified. 


\section{Material and methods}

Skull collections at the Swedish Museum of Natural History, Stockholm were used for the analyses. All animals had been sampled in the central part of the Baltic Sea, excluding gulfs.

To avoid the problems of age determination and possible effects of age on the studied characters of skull morphology, only pups (ie animals sampled at the age not older than one year) have been used in this study. Using these limits, it was possible to select 15 skulls of the ringed seal born in the period from 1897 till 1933 (I - pre-pollution sample), 14 skulls of animals born in 1973-1975 (II - high-pollution sample), and 15 skulls of animals born in 1988-1990 (III - low-pollution sample); and 20 skulls of the grey seal for each of three compared periods: of 1877-1936 (I - pre-pollution sample), 1964-1975 (II - high-pollution sample), and 1986-1990 (III - low-pollution sample).

We have used the set of 15 characters, consisting of bilateral foramen in the skull (foramen are openings through the bone for nerves and small blood vessels) (Fig. 2). Some of these characters were

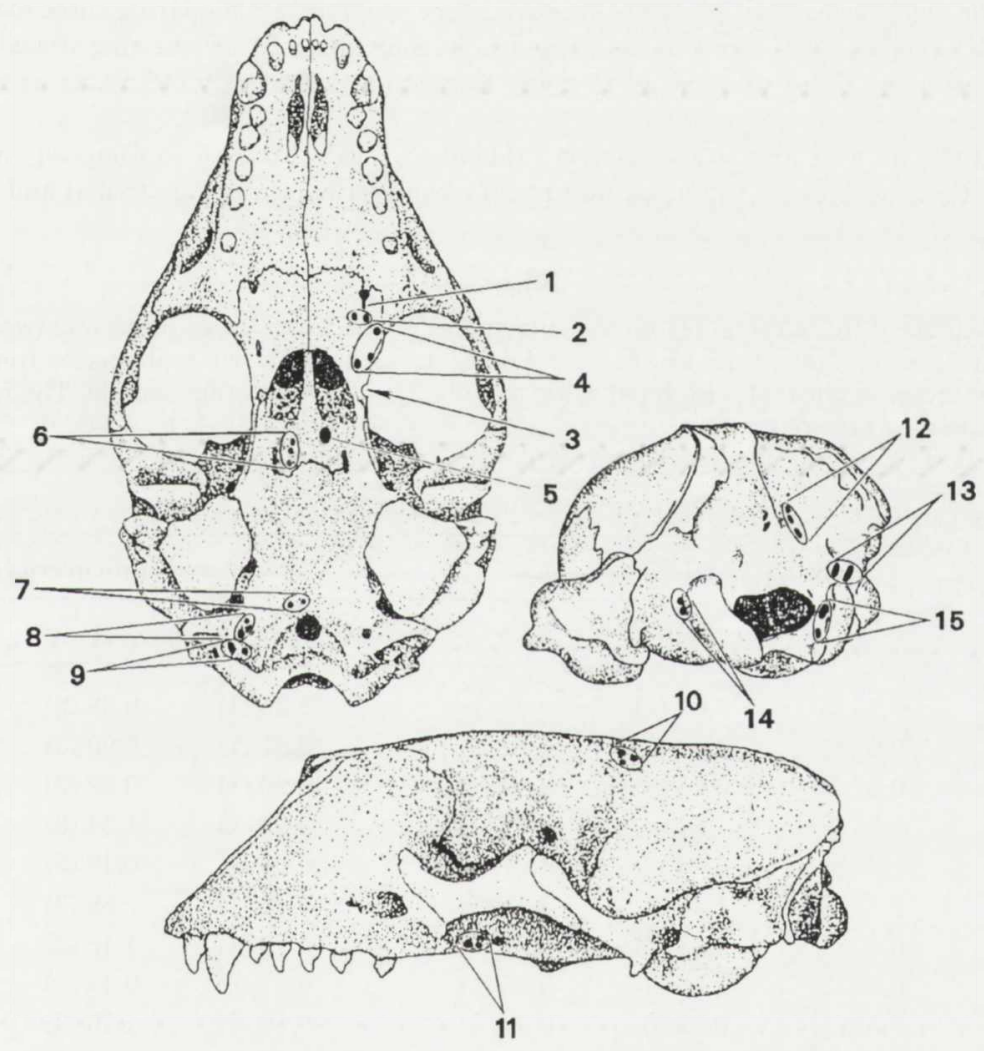

Fig. 2. Cranial characters, as a number of foramen (1-15), examined in the grey seal Hali-choerus grypus (from Zakharov and Yablokov 1990, modified): 1 - sulculus foramen palatinae major, 2 foramen palatinae major posterior, 3 - foramen palatinae minor incomplete, 4 - foramen palatinae, 5 - foramen sphenoidalis lateralis major, 6 - foramen sphenoidalis lateralis minor, 7 - foramen basioccipitalis accessorius, 8 - foramen hypoglossum basilaris, 9 - canalis condylaris ventralis, 10 -foramen squamata frontalis, 11 - foramen basiorbitalis accessorius, 12 - foramen occipitalis accessorius, 13 - fenestra occipitalis lateralis, 14 - canalis condylaris dorsalis, 15 - foramen hypoglossum intracondilaris. 
previously studied by Berry (1969) in his study of British grey seals. All the characters are described and defined in Zakharov and Yablokov (1990).

The value of asymmetry in each sample for each character was estimated by variance for difference in number of foramen on the left and right side (l-r) and for difference divided by sum $(1-r) /(l+r)$. As no significant directional asymmetry and antisymmetry had been found for the characters analyzed we considered asymmetry under study as fluctuating asymmetry (Palmer and Strobeck 1986). Additionally, the mean number of asymmetrical characters for the whole set of analyzed characters per individual has been used as an integrated measure of developmental stability (Leary et al. 1983).

To test the correlation between the characters for the $(l+r)$ values as well as for the $(1-r)$ values commonly used parametric coefficient of correlation at the individual level and non-parametric Kendalls coefficient of concordance at the sample level have been used. No significant correlation between characters for the $(l+r)$ and $(l-r)$ values at the individual level have been found in either species (only two significant values revealed in all possible paired comparison of 15 characters for both indices for two species most probably appeared here by chance). Comparing three samples under study, Kendall's coefficient of concordance proved to be 0.69 and 0.81 for the ringed seal and for the grey seal, respectively. That allowed us to apply fluctuating asymmetry estimates as a population parameter.

The $F$-statistic as well as non-parametric Friedman's test were used to compare variances and Student's $t$-statistic to compare the mean number of asymmetrical characters (Sokal and Rohlf 1981).

Table 1. The values of fluctuating asymmetry (variance for the unscaled difference between two sides of the body for 15 skull characters, see Fig. 2) of different samples of two seal species from the Baltic Sea. I - pre-pollution sample, II - high-pollution sample, III - low-pollution sample. The rank for each value is presented in brackets.

\begin{tabular}{|c|c|c|c|c|c|c|}
\hline \multirow{3}{*}{$\begin{array}{l}\text { Number of } \\
\text { character }\end{array}$} & \multicolumn{6}{|c|}{ Samples } \\
\hline & \multicolumn{3}{|c|}{ Ringed seal Pusa hispida } & \multicolumn{3}{|c|}{ Gray seal Halichoerus grypus } \\
\hline & I & II & III & I & II & III \\
\hline 1 & $0.14(3)$ & $0.07(2)$ & $0.06(1)$ & $0.26(1)$ & $0.38(2)$ & $0.95(3)$ \\
\hline 2 & $0.07(1)$ & $0.90(3)$ & $0.12(2)$ & $0.31(1)$ & $0.90(3)$ & $0.52(2)$ \\
\hline 3 & $0.07(2)$ & $0.75(3)$ & $0.001(1)$ & $0.20(1)$ & $0.42(3)$ & $0.37(2)$ \\
\hline 4 & $0.35(2)$ & $1.91(3)$ & $0.27(1)$ & $0.59(1)$ & $1.54(3)$ & $1.01(2)$ \\
\hline 5 & $0.21(1.5)$ & $0.29(3)$ & $0.21(1.5)$ & $0.05(1)$ & $0.19(2)$ & $0.20(3)$ \\
\hline 6 & $0.35(2)$ & $1.46(3)$ & $0.21(1)$ & $0.48(1)$ & $2.59(3)$ & $1.04(2)$ \\
\hline 7 & $0.07(1)$ & $2.11(3)$ & $0.27(2)$ & $0.13(1)$ & $1.16(3)$ & $0.53(2)$ \\
\hline 8 & $0.64(2)$ & $0.90(3)$ & $0.35(1)$ & $0.37(2)$ & $0.47(3)$ & $0.35(1)$ \\
\hline 9 & $0.35(2)$ & $0.90(3)$ & $0.07(1)$ & $0.10(1)$ & $1.85(3)$ & $1.27(2)$ \\
\hline 10 & $0.60(2)$ & $1.76(3)$ & $0.35(1)$ & $0.26(1)$ & $2.54(3)$ & $0.56(2)$ \\
\hline 11 & $0.14(1.5)$ & $1.48(3)$ & $0.14(1.5)$ & 0.37 (1) & $1.13(3)$ & $0.41(2)$ \\
\hline 12 & $0.07(1)$ & $4.86(3)$ & $2.03(2)$ & $0.31(1)$ & $5.41(3)$ & $1.84(2)$ \\
\hline 13 & $0.35(2)$ & $0.58(3)$ & $0.21(1)$ & $0.66(1)$ & $1.36(3)$ & $1.10(2)$ \\
\hline 14 & $0.12(1)$ & $0.84(3)$ & $0.29(2)$ & $0.10(1)$ & $1.53(3)$ & $0.41(2)$ \\
\hline 15 & $0.14(2)$ & $0.31(3)$ & $0.00(1)$ & $0.16(1)$ & $0.56(3)$ & $0.20(2)$ \\
\hline Sum of ranks & (26) & (44) & $(20)$ & (16) & $(43)$ & (31) \\
\hline
\end{tabular}




\section{Results}

Comparison of the values of fluctuating asymmetry in three samples shows significant differences between them in nearly all characters for both species (Table 1). An increase of the value of fluctuating asymmetry for sample II comparing with the two others, is manifested in 14 characters for the ringed seal and in 13 characters for the grey seal. It is clearly the same trend in both species, but there are some interspecific differences in relations between the samples I and III. The values of fluctuating asymmetry are similar for the samples I and III in ringed seal, while in grey seal there is a clear tendency for the higher values of asymmetry in sample III as compared with sample I. Such a tendency is visible for almost each separate character (Table 1). Friedman's test revealed significant and concordant changes in the values of asymmetry variance between the three compared samples (being equal 20.80, $p<0.001$ for the ringed seal, and 24.40, $p<0.001$ for the grey seal, respectively).

Analysis of the variances for the scaled asymmetry values revealed the same pattern for the differences between the samples. Furthermore, changes in the mean number of asymmetrical characters, as another integrated measure of developmental stability, showed the same pattern (Table 2).

Table 2. Differences between integrated measures of developmental stability presented as mean number of asymmetrical characters (NA $\pm \mathrm{SE}$ ) for the set of 15 skull characters (see Fig. 2) in different samples of two seal species from the Baltic Sea (see Table 1). Statistical significance (Student's $t$-test) is given as $p$.

\begin{tabular}{llcrcc}
\hline Species & Sample & $n$ & NA \pm SE & $p$ & $\begin{array}{c}\text { Samples } \\
\text { compared }\end{array}$ \\
\hline Ringed seal & I & 15 & $3.00 \pm 0.31$ & $<0.001$ & I-II \\
Pusa hispida & II & 14 & $10.21 \pm 0.30$ & $<0.001$ & II-III \\
& III & 15 & $2.80 \pm 0.46$ & ns & I-III \\
Grey seal & I & 20 & $3.65 \pm 0.30$ & $<0.001$ & I-II \\
Halichoerus grypus & II & 20 & $10.42 \pm 0.37$ & $<0.001$ & II-III \\
& III & 20 & $6.75 \pm 0.46$ & $<0.001$ & I-III \\
\hline
\end{tabular}

\section{Discussion}

Developmental stability was established as one of the most general ontogenetic characteristics useful for biomonitoring to estimate the condition of natural populations (Valentine et al. 1973, Jones 1987, Leary and Allendorf 1989, Zakharov 1989, 1990). Applying to the study of samples of the Baltic seals collected at different time characterized by essentially different levels of pollution, mechanism of possible changes in developmental stability can be described as following. 
Increased environmental stress caused by the higher pollution can change the physiological condition of pregnant females, leading to the disturbance in developmental stability of their progeny. Such physiological response to stress should be reversible, ie decreased developmental stability can recover to the common level in the following generations developed under normal conditions. Deterioration of developmental stability of the progeny caused by the environmental stress of the pregnant females has been established experimentally and in natural populations for the small mammals (Siegel et al. 1977, Zakharov et al. 1991).

Comparison of three temporally different samples of seals representing different levels of pollution of the Baltic Sea revealed the same pattern of change in developmental stability when measured by fluctuating asymmetry of skull characters. It proved to be low for the "pre-pollution groups", high for the "high-pollution groups" and again low for the "low-pollution groups". Thus, the data obtained suggest changes in the condition of the seal populations in the Baltic Sea revealed by dramatic fluctuations in the level of developmental stability.

Precise detection of the inputs of each pollutant in revealed changes in condition of seal populations is hardly possible. However, general concordance of dynamics of developmental stability and pollution of the Baltic Sea, and organochlorines in particular, seems to be clear.

In spite of the similarity in general pattern of dynamics in developmental stability revealed for both seal species there are some differences. Thus, for the ringed seal as the most common seal species in the Baltic Sea, the level of developmental stability revealed for the modern sample corresponds to the level detected for the sample collected before the beginning of the dramatic pollution in the Baltic Sea. For the grey seal, in spite of some evidences of improvement, situation still is rather serious: level of developmental stability is higher comparing with the most dangerous time of pollution, but still is less than it was in pre-pollution time. This difference between two species corresponds to their modern ecological status in the Baltic Sea, ie situation for the ringed seal population is better than for the grey seal population. Different reactions of these two species on the same environmental impact could be caused by species specific life history parameters or sensitivity to the pollutants.

Significant changes in developmental stability were revealed by comparing the pooled samples collected from various localities in different years for 15 skull characters instead of 32 characters used in the previous study (Zakharov and Yablokov 1990). This imply that the general trend for the population condition dynamics could be detected by developmental stability estimates for the limited set of phenotypic characters on relatively small population samples.

The results of this study indicate that changes in the measures of developmental stability are parallel to the changes in the level of pollution that allow to monitor the dynamics of the condition of natural populations during the increase and decrease of the environmental impact. The fact that such an estimation of developmental stability can be limited by the morphological characters study 
provides an opportunity to monitor the dynamics of the population status on the museum collections.

Acknowledgements: The work has been supported by the exchange program between the USSR State Committee of Nature Protection and the Swedish National Environmental Protection Agency in the field of environment protection. We are very grateful to Prof M. Olsson at the Swedish Museum of Natural History for the help at each step of this work and to Mr A. Stanzak for the help in using the collection of the museum. We are very grateful to Dr J. H. Graham and two anonymous referees provided very helpful comments and corrections of English.

\section{References}

Bergman A. and Olsson M. 1985. Pathology of Baltic gray seal females with special reference to adrenocortical hyperplasia: Is environmental pollution the cause of a widely distributed disease syndrome? Finnish Game Research 44: 47-62.

Berry R. J. 1969. Non-metrical skull variation in two Scottish colonies of the gray seal. Journal of Zoology, London 157: 11-18.

Blomkvist G., Ross A., Jensen S., Bignert A. and Olsson M. 1992. Concentration of sDDT and PCB in seals from Swedish and Scottish Waters. Ambio 21: 539-545.

Helle E., Olsson M. and Jensen S. 1976a. DDT and PCB levels and reproduction in ringed seal from the Bothnian Bay. Ambio 5: 188-189.

Helle E., Olsson M. and Jensen S. 1976b. PCB levels correlated with pathological changes in seal uteri. Ambio 5: 261-263.

Johnes J. S. 1987. An asymmetry view of fitness. Nature 325: 298-299.

Leary R. F. and Allendorf F. W. 1989. Fluctuating asymmetry as an indicator of stress: implications for conservation biology. Trends in Ecology and Evolution 4: 214-217.

Leary R. F., Allendorf F. W. and Knudsen K. L. 1983. Developmental stability and enzyme heterozygosity in rainbow trout. Nature 301: 71-72.

Mather K. 1953. Genetic control of stability in development. Heredity 7: 297-336.

Olsson M., Johnels A. G. and Vas R. 1975. DDT and PCB levels in seals from Swedish waters. The occurrence of aborted seal pups. Report from the National Swedish Environmental Protection Agency 591: 43-65.

Olsson M. and Reutergärdh L. 1986. DDT and PCB pollution trends in the Swedish aquatic environment. Ambio 15: 103-109.

Palmer R. A. and Strobeck C. 1986. Fluctuating asymmetry: measurement, analysis, patterns. Annual Review in Ecology and Systematic 17: 391-421.

Pankakoski E., Koivisto I. and Hyvarinen H. 1992. Reduced developmental stability as an indicator of heavy metal pollution in the common shrew, Sorex araneus. Acta Zoologica Fennica 191: 137-144.

Siegel M. I., Doyle W. J. and Kelley C. 1977. Heat stress, fluctuating asymmetry and prenatal selection in the laboratory rat. American Journal of Physiological Anthropology 46: 121-126.

Sokal R. R. and Rohlf F. J. 1981. Biometry. Freeman, San Francisco: 1-859 .

Valentine D. W. and Soulé M. 1973. Effect of p.p'-DDT on developmental stability of pectoral fin rays in the grunion, Leuresthes tenuis. Fishery Bulletin 71: 921-926.

Valentine D. W., Soulé M. and Samollow P. 1973. Asymmetry analysis of fishes: a possible statistical indicator of environmental stress. Fishery Bulletin 71: 357-370.

Zakharov V. M. 1981. Fluctuating asymmetry as an index of developmental homeostasis. Genetika (Beograd) 13: 241-256.

Zakharov V. M. 1987. [Animal asymmetry: population-phenogenetic approach.] Nauka, Moskva: 1-216. [In Russian]

Zakharov V. M. 1989. Future prospects for population phenogenetics. Soviet Science Reviews, Section F 4 (3): 1-79. 
Zakharov V. M. 1990. Analysis of fluctuating asymmetry as a method of biomonitoring at the population level. [In: Bioindications of chemical and radioactive pollution. D. A. Krivolutsky, ed]. Mir, Moscow: 188-198.

Zakharov V. M., Esipenko A. G. and Filatov I. E. 1989a. Are there differences in the level of developmental stability between the Baltic and Ladoga populations of ringed seal (Pusa hispida botnica and $P$. h. ladogensis)? [In: Influence of human activities on the Baltic ecosystem. A. V. Yablokov and M. Olsson, eds]. Gidrometeoizdat, Leningrad: 109-116.

Zakharov V. M., Olsson M., Yablokov A. V. and Esipenko A. G. 1989b. Does environmental pollution affect the developmental stability of the Baltic grey seal (Halichoerus grypus)? [In: Influence of human activities on the Baltic ecosystem. A. V. Yablokov and M. Olsson, eds]. Gidrometeoizdat, Leningrad: $96-108$.

Zakharov V. M., Pankakoski E., Sheftel B. I., Peltonen A. and Hanski I. 1991. Developmental stability and population dynamics in common shrew, Sorex araneus. American Naturalist 138: 797-810.

Zakharov V. M. and Yablokov A. V. 1990. Skull asymmetry in the Baltic gray seal: effect of environmental pollution. Ambio 19: 266-269.

Received 11 October 1995, revised 10 October 1996, accepted 15 March 1997. 